\title{
The Rise and Fall of Training and Visit Extension: An Asian Mini-drama with an African Epilogue
}

\author{
by \\ Jock R. Anderson, Gershon Feder and Sushma Ganguly \\ Agriculture and Rural Development Department \\ World Bank
}

World Bank Policy Research Working Paper 3928, May 2006

The Policy Research Working Paper Series disseminates the findings of work in progress to encourage the exchange of ideas about development issues. An objective of the series is to get the findings out quickly, even if the presentations are less than fully polished. The papers carry the names of the authors and should be cited accordingly. The findings, interpretations, and conclusions expressed in this paper are entirely those of the authors. They do not necessarily represent the view of the World Bank, its Executive Directors, or the countries they represent. Policy Research Working Papers are available online at http://econ.worldbank.org. 
The Rise and Fall of Training and Visit Extension:

An Asian Mini-drama with an African Epilogue

\begin{abstract}
$\underline{\text { Abstract }}$
The paper reviews the origins and evolution of the Training and Visit (T\&V) extension system, which was promoted by the World Bank in the period 1975-1998 in over 50 developing countries. The discussion seeks to clarify the context within which the approach was implemented, and to analyze the causes for its lack of sustainability and its ultimate abandonment. The paper identifies some of the challenges faced by the T\&V approach as being typical of large public extension systems, where issues of scale, inadequate interaction with the agricultural research systems, inability to attribute benefits, weak accountability, and lack of political support tend to lead to incentive problems among staff and managers of extension, and limited budgetary resources. The different incentives and outlook of domestic stakeholders and external donor agencies are reviewed as well. The main cause of the T\&V system’s disappearance is attributed to the incompatibility of its high recurrent costs with the limited budgets available domestically, leading to fiscal unsustainability. The paper concludes with some lessons that apply to donor-driven public extension initiatives, and more generally to rural development fads. The role of timely, independent, and rigorous evaluative studies is specifically highlighted.
\end{abstract}




\title{
The Rise and Fall of Training and Visit Extension: An Asian Mini-drama with an African Epilogue
}

\author{
Jock R. Anderson, Gershon Feder and Sushma Ganguly ${ }^{1}$
}

\section{Introduction}

Within the voluminous literature on agricultural extension experiences, the emergence, widespread diffusion, and ultimate disappearance of the Training and Visit extension system has received much attention. Various country-specific or generalized discussions were contributed over the years. The purpose of this chapter is to pull together these insights and observations so as to provide an analytical narrative of the dramatic international rise and fall of T\&V extension. To tell a coherent story requires utilizing a conceptual framework explaining the organizational behavior of public extension systems and the incentives of their staff and management, as well as the behavior and incentives of external donor agencies. Thus, following the next section, which provides a general description of the pre-T\&V extension scene, we sketch the general behavioral patterns underlying our discussion. This is followed by a brief description of the principles of the $\mathrm{T} \& \mathrm{~V}$ system and their rationale and merits, as well as their likely deficiencies. The subsequent section of the chapter describes the evolution of the system in Asia and Africa (there was no significant presence of $\mathrm{T} \& \mathrm{~V}$ extension in Latin America). The final section provides concluding remarks that attempt to generalize the insights gained. In view of the dominant role of the World Bank in the development and spread of T\&V extension, there will be heavy reliance on the actions, studies and deliberations of the World Bank, although other sources are utilized.

\footnotetext{
${ }^{1}$ The authors are with the World Bank, Washington, DC. Seniority of authorship is not assigned. The findings, interpretations, and conclusions expressed in this paper are entirely those of the authors. They do not necessarily represent the views of the International Bank for Reconstruction and Development / World Bank and its affiliated organizations, or those of the Executive Directors of the World Bank or the governments they represent.
} 


\section{Extension in the Post-Colonial Era}

In the immediate aftermath of the dismantling of colonialism, agricultural extension organizations in developing countries followed generally the administrative structures of the colonial era (Axinn and Thorat, 1972). The main focus was on supporting the production and marketing of export crops. Gradually, the newly independent countries shifted more attention to food production, and their extension services evolved to serve a large clientele of smaller farmers rather than the export crop estates. The production orientation of earlier years was often modified to include more general support to various aspects of farmers' activities, such as community work, credit, input supplies, nutrition, family planning (e.g., Anderson and Hoff, 1993). A common perception among policymakers and agricultural officials in those times was that farm productivity growth was constrained by farmer backwardness, inadequate organization, and deficient local leadership. Accordingly, in the 1950s and 1960s, extension agents operated within multipurpose development programs and village development initiatives. In many instances, they were administratively assigned to local governments or to central ministries other than agriculture, or were accountable to more than one agency (Picciotto and Anderson, 1997).

The next section explains the factors underlying the observed performance of public extension and the political and bureaucratic environment in which they operated. This will provide the background for the emergence of the T\&V extension model, which aimed at overcoming some of the prevalent deficiencies. 


\section{A Characterization of Extension Organization Behavior}

Many scholars and observers of rural development commented on the frequent manifestations of unsatisfactory extension performance (e.g., Rivera, Qamar and Crowder, 2001). The common incidence of such performance issues across many developing countries is highlighted by Feder, Willett and Zijp (2001), who identified eight interrelated characteristics that are inherent in public extension systems, and which jointly lead to inadequate performance. These characteristics tend to be generic and could be applicable to any sector/subsector, but we highlight below why they have been more binding constraints in the case of the extension programs.

1. Scale and complexity: The cost of reaching large, geographically dispersed and remote smallholder farmers is high, particularly given high levels of illiteracy, limited access to mass media, and high transport costs. Farming systems often entail several crops, livestock, and even within given geographical area, there are variations in soil, elevation, microclimate and farmers' capabilities and access to resources. With such a large and diversified clientele, only a small fraction of farmers can be served directly (face-to-face) by extension, and agents tend to focus on the larger, better resourced and more innovative farmers. This reduces the potential for farmerto-farmer diffusion. Limited outreach to smallholder clientele reduces the benefits and impact of extension.

2. Dependence on broader policy environment: The outcome of extension efforts depends on policies over which agents and their managers have little influence (input and output prices, credit policies, input supplies, marketing and infrastructure system). The policy 
environment can indeed affect any investment, but more so for extension programs, particularly if the advice is not adjusted to reflect the incentive environment in which farmers operate.

3. Interaction with knowledge generation: Public extension and research systems often compete for budget, but research institutions have an advantage due to their higher status, better management quality, and links with the global science community. This creates tensions and militates against an effective two-way communication (e.g., Mureithi and Anderson, 2004). The dependence of extension programs on science and technology (and generation thereof) and viceversa is strong, i.e., the linkage effect is more important than it is among other sub-sectors, and yet research scientists do not have strong incentives to interact with extension.

4. Difficulty in attributing impact: Attribution of impact is an analytically challenging task in the case of extension programs, due to the lack of baseline information, unavailability of appropriate control groups, and the systemic biases in extension placement and contacts (Birkhaeuser, Evenson and Feder, 1991). Given the difficulty of attributing outcomes, managers focus on collecting the reporting input indicators (visits made, meetings and field days arranged, sample kits distributed), that are easier to assemble, and the incentives to deliver high-quality information service is weak (Martens et al., 2002, p. 20).

5. Weak accountability: Weak accountability (linked to the inability to attribute impact) is reflected in low-quality and repetitive advice given to farmers, and in diminished effort to interact with farmers, and to learn from their experience. There are no mechanisms, or 
incentives to create mechanisms (e.g., participatory processes) for fostering accountability to clients who can best observe the quality and quantity of extension input.

6. Weak political commitment and support: Feder, Willett and Zijp (2001) suggest that highly visible irrigation or road projects are more attractive to politicians than extension expenditures. This, compounded by difficulties in attribution of impact, makes extension an easy target for lower budgetary support.

7. Public duties other than knowledge transfer: Governments are often tempted to use field-level cadres of public servants who are already present in the countryside for non-extension duties such as collection of statistics, distribution of subsidized inputs, assisting and collecting loan applications, and election campaign work on behalf of local or national ruling parties.

8. Financial unsustainability: This can cause the demise of any investment program but it is observed that at times of general fiscal constraints, extension budgets are more likely to be squeezed due to weak political support. Due to the large share of staff costs in the recurrent costs, and the rigidity of public personnel policies, field operations (including maintenance of equipment and buildings, and training) provide the most flexible cost-cutting budget items.

While the discussion above provides rationale for the weak performance of extension, and the limited popularity of extension spending with national politicians and senior officials, one observes a much greater enthusiasm and support for funding extension among managers and staff in external donor agencies and nongovernmental organizations (NGOs). The NGOs typically operate at a small scale (tailored to the limited external budgets they can provide) and 
their activities are on a full grant basis, not requiring local government funding. They are therefore less concerned with issues of fiscal sustainability. They overcome the various incentive problems by deploying external or local advisors who work closely with local extension at the field level, thus providing effective supervision. And they often have access to better-quality, more committed field advisors, through the higher pay levels they provide. Thus, NGO-supported extension initiatives often are perceived to (and may in fact) have better performance, but they cannot be realistically scaled up to national level with the same level of staffing and performance. Small bilateral donors often operate in a similar mode to that of NGOs.

The incentives and explanations are different for large external donor agencies, which cannot have extensive field presence in the large extension projects they finance. An explanation of their support for extension projects, focusing on extension systems at the national level (or large sub national units) is provided by Anderson and Feder (2004). Often a small pilot or a small component within another project, with heavy supervision or other conducive circumstances (e.g., irrigation development, or delivery of abundant subsidized inputs, or simply the small and easily-managed scale) will create a perception (often justified) of success. The extension model of the small-scale pilot will then be promoted to both the donor agency management and to developing-country policymakers as worthy of scaling up to the national level. The traditional reluctance of national policymakers is temporarily overcome by the availability of abundant external funds that are provided outside of the normal budget framework. Ministry of Finance officials, who normally are averse to the implied long-term liabilities entailed with expanding staff-intensive systems, do not know enough about agriculture 
and extension, and may be impressed with the output growth projections based on extrapolations from the small-scale pilots. Local extension and agricultural bureaucracies are supportive of the expansion as the external funding provides resources to improve their infrastructure, expand their organizations, and boost their status. The implicit rivalry with the research system is often overcome when the foreign-financed program focuses on both research and extension, or apportions some external funding for research organization-executed activities within a national extension project.

From the perspective of a large external donor, the upscaling of a pilot extension model to the national level is relatively simple to design, involving only one counterpart agency (the Ministry of Agriculture, or a couple of specialized agencies within it), thus reducing bureaucratic complexity. The activities funded within the project are well defined inputs: construction and refurbishing of extension offices and staff housing, procurement of vehicles, motorcycles (even bicycles), training activities, funding of additional personnel, etc. A national-scale project entails a large loan or grant, while the preparation cost to the donor is not proportionately as high due to the ability to extrapolate from the parameters derived from the pilot project. The cost of project preparation per dollar granted or lent is thus not high. Furthermore, repeated projects are easy to process. Extension projects do not present a hurdle as they do not require a rigorous ex-ante cost-benefit analysis (which confronts hardware-type projects). Moreover, the difficulty of attributing impact implies that it will be almost impossible to establish a definite failure at the end of the implementation period. Thus, the bureaucratic risk for the promoter of the project is only the possibility of flagrant non-implementation of the input side of the project (e.g., nonfilling of agreed staffing levels, or no construction of agreed structures, or curtailing of field 
operations due to inadequate recurrent budget transfers from government). These are relatively low risks during the external-funded phase of an extension program and, even if they materialize, the cause of the failure can be assigned to the government rather than to a faulty design concept or to insufficient verification of the availability of viable technology to disseminate.

There are, therefore, strong incentives for external donor staff to promote large extension programs, and the local lack of enthusiasm can be overcome temporarily, for a couple of project cycles (10-12 years). Ultimately, senior donor officials expect extension activities to be absorbed in the normal budget process of the recipient country, as the external funding is viewed by them as a one-time investment cost. But if the expanded extension system entails a much larger recurrent (as well as equipment replacement) cost than that which is normally politically supported, a moment of truth is eventually faced. The local budgets will be drastically or gradually reduced, with a major negative impact to be observed in field operations (i.e., diminished interactions with farmers), as staff levels can only slowly be reduced. Alternatively, extension staff will be diverted into other (non-extension) agricultural or community activities for which budgetary resources are available. Extension size, or the volume of extension information dissemination activities, will thus converge to those dimensions that are compatible with political realities (e.g., Purcell and Anderson, 1997).

This projected scenario may span a somewhat longer time period in heavily donordependent, very poor, countries. The reason is that, in such countries, a significant proportion of government budget is derived from donor funding directly or indirectly, and recurrent costs are routinely funded (at least indirectly) to a significant extent by external donors. The concept of 
"mainstreaming" (i.e., absorbing into the normal budget process) of a larger extension organization is therefore less applicable, and senior donor management can be persuaded to support extension funding over a longer horizon. Furthermore, local policymakers are more receptive to what is perceived as donors' strong advice due to their dependence on external funding, thus misgivings about the priority given to extension are often not voiced too forcefully. One would thus expect that large donor-supported extension systems will tend to last longer in donor-dependent Africa than in Asia.

\section{The Advent of Training and Visit Extension}

In the late 1960s and early 1970s, technology diffusion became the key focus of agricultural extension systems. The rationale for shift was eminently apparent: new high yielding varieties for staple cereals were released by international research centers, and adapted by national research systems. This coincided with higher output prices due to food scarcity making dissemination efforts likely to meet receptive farmers (Lipton with Longhurst, 1989). Yet, extension systems of the time were viewed as not very effective.

The concept of Training and Visit (T\&V) extension was developed in the early 1970s, and implemented as a component in two regional irrigation projects, the Seyhan (Phase 2) project in Turkey, and the Chambal (Rajasthan and Madhya Pradesh) project in India, both funded by the World Bank in 1974. The principles of the system were spelled in great detail in Benor and Harrison (1977) and Benor and Baxter (1984), and are well familiar to most rural development scholars. We recount them briefly with an interpretation demonstrating that they 
were designed to overcome some of the inherent weaknesses of public extension systems outlined in Section III.

(i) A hierarchical organization with several layers of management overseeing a large cadre of village level workers under a single line of command, so that extension workers are not controlled by, or responsible to, other authorities (such as communal leadership or special croporiented organizations). The organization included subject matter specialists who were the technical resource staff.

(ii) A rigid bi-weekly schedule of visits to a defined fixed list of contact farmers (later modified to contact groups) in specific villages within a village worker's area of responsibility. The contact farmers (or groups) were expected to disseminate information further to other farmers within the community.

(iii) Fortnightly regular training of village level workers, administered by superiors and subject matter specialists, and focused on the information to be delivered in the coming couple of weeks.

(iv) No involvement of the extension organization and its field level workers in non-extension duties, such as input distribution and loan applications. Extension staff were to handle only agricultural information services. 
(v) Regular interactions (through seasonal workshops) of extension's leaders and subject matter specialists with research station scientists. Specialists were expected to conduct their own on-farm research.

(vi) Concentration on the most important crops, and on messages about relatively simple lowcost improved practices.

The hierarchical structure, and the strict schedule of visits to predetermined contact farmers, whose names and time of visits were known to supervisors, was designed to overcome the weak incentives to interact with farmers on information delivery. The single line of command and prohibition on non-extension duties was intended to overcome the temptation to assign (by higher level officials) and undertake (by extension workers) potentially remunerative duties not involving information dissemination. Thus, the design improved the accountability of village-level workers to their superiors with respect to the quantity of their work, but not with respect to quality. In the absence of accountability to farmers, quality and impact were still difficult to observe, although the frequent and mandatory training was intended to improve the overall knowledge of workers and overcome their disincentives to invest in improving their skills. Feedback from farmers through village workers to supervisors and subject matter specialists was theoretically feasible during the training sessions. But the incentives for staff to solicit such feedback and report it were not much changed, compared to the past, in the absence of accountability to farmers. Some $\mathrm{T} \& \mathrm{~V}$ projects (notably in India) had built-in units for monitoring and evaluation (M\&E) that were designed to provide management with feedback, both on the mechanics of the system (visits, training sessions), as well as on impact, but the typical skill profiles of those likely to serve in such units were not adequate to perform reliable 
attribution analysis. Furthermore, these M\&E units were structured to be under the authority of extension management, so their independence was compromised. As a result, the inability to attribute the extension system's impact convincingly at the aggregate level, and thereby to gain the support of policymakers, was still a problem under the $\mathrm{T} \& \mathrm{~V}$ design.

The pre-designed interaction with research, and the structured positions for subjectmatter specialists, whose mandate required regular contact with research, were to overcome the weakness in this field. But the incentives for research scientists to invest heavily in interaction with extension have generally been slow to change if at all, so there were limits to the progress that could be achieved in this respect.

The large clientele was to be served by a larger field-level cadre than before. This, as well as many other features of the design (multi-level hierarchy with more mid-level managers and technical experts, better mobility through vehicles and motorcycles, more local-level offices) implied not only a higher investment cost, but also a much higher recurrent cost compared to the pre- $\mathrm{T} \& \mathrm{~V}$ situation. This is reflected in the fact that 90 percent of completed $\mathrm{T} \& \mathrm{~V}$ extension projects reviewed in Purcell and Anderson (1997) encountered serious recurrent cost funding shortages, some even while the project was still under implementation. In our judgment this is the most crucial aspect responsible for the ultimate fall of the T\&V extension model within a 25year period from its inception in 1974, rather than the fact that the design contained features that limited the improvement in effectiveness. The promoters of $\mathrm{T} \& \mathrm{~V}$, while being aware of the cost, did not appreciate the political ramifications of high recurrent costs. Thus, Development Communication Report (1978, p. 9) cited a key leader of the T\&V concept in response to a 
question on the high cost of the system: "cost is scarcely a consideration. No country in the world can afford not to spend this money”.

The deficiencies in effectiveness (in the many places where such was the situation) could not be easily detected and linked rigorously to poor outcomes at the farm level, and it is unlikely to have caused by itself a disenchantment with $\mathrm{T} \& \mathrm{~V}$ by agricultural policymakers. It is thus the higher cost, combined with the lack of convincing evidence of major gains attributable to extension, which most probably induced the fall of $\mathrm{T} \& \mathrm{~V}$.

\section{The Spread and Decline of T\&V Extension}

Following the formal introduction of T\&V extension components in the Chambal Irrigation Command (Rajasthan and Madhya Pradesh states in India) and the Seyhan Irrigation project in Turkey in 1974, World Bank staff associated with the projects provided enthusiastic feedback on the contribution of extension in these projects, and attributed significant on-farm gains to the extension reforms. The on-farm changes in these project areas have never been analyzed rigorously. It is quite likely that favorable farm performance was indeed observed in the project areas. But it as likely that such improvements were due in some part to the better management of the irrigation services, more timely availability of inputs, and the close attention of World Bank staff in a relatively confined project area (Moore, 1984). Furthermore, it is easier to manage a relatively small extension staff in an irrigation command area, operating within a fairly homogenous farming system. But concerns regarding the legitimacy of extrapolating from these apparently successful smaller scale projects to the state or national level did not seem to have been raised forcefully. 
Thus, the perceived success induced World Bank staff and management to actively promote the adoption of the T\&V extension model in India and other countries even before the completion of the two irrigation projects. This campaign, backed by readily available funding from the World Bank, was undertaken with such zeal and dedication that some observers likened it to the fervor of a religious movement (Moore, 1984, p. 307). The spread of the new concept was dramatic: By the end of 1982, the system was introduced in 13 states of India (with four more states in the next few years). In the same period (1975-1982), T\&V extension was introduced with World Bank funding in ten additional countries (mostly in Asia) through selfstanding extension projects, and in nine additional countries as components of larger agricultural projects in Asia and Africa. Other donors, such as the International Fund for Agricultural Development (IFAD) and the FAO adopted the approach (or aspects of it) in their operations as well. Later in the 1980s, additional countries adopted the approach, and many of the projects that were initiated in the 1970s and early 1980s were continued or expanded (with new funding from the World Bank) in second-phase operations. Altogether, close to fifty developing countries utilized some form of $\mathrm{T} \& \mathrm{~V}$ extension during the period 1974-1999. However, as second-phase projects in India and other large Asian countries were being completed, in the late 1980s and early 1990s, there were no new foreign-funded programs, as the external donors expected that these systems were already "mainstreamed". Thus, the extension systems had to be maintained through national or state budget only. In Africa, however, there were still new or follow-up projects through the 1990s with the last one funded by the World Bank in 1998 in Cameroon. 
It was inevitable that such a global effort attracted critical attention of development scholars and practitioners. Critical comment focused on both systemic areas of weakness of public extension systems, as well as on features that were more specific to the $T \& V$ design and the manner in which it was implemented. The earliest significant criticism is in the collection edited by Howell (1982a), which engendered a heated debate (Howell, 1982b), and was further elaborated by Howell (1983). The next significant forum in which serious concerns regarding the effectiveness of the $\mathrm{T} \& \mathrm{~V}$ model were prominently highlighted was a 1983 workshop in the National Institute for Rural Development in Hyderabad, India. These concerns, pertaining to the experience in several Indian states, were summarized by Moore (1984). Some of the problems related to aspects of $\mathrm{T} \& \mathrm{~V}$ that could not be fully implemented. Moore recounts reports of cases where the regular training sessions were not being held, or lacked real content; officers appointed as subject matter specialists without having adequate qualifications; linkages with research not quite enhanced; village agents not following the regular visit schedule, or contact farmers not attending visits, with some of them not being aware that they were designated as contact farmers. The common preference of agents to interact with larger scale and richer farmers was said to still be present under the T\&V system. And insufficient attention to the supply conditions of inputs hampered the relevance of the information conveyed to farmers. According to Moore (1984), the supervisory staff did not have incentives to use the strict visit schedule as a device to enforce work delivery by village workers, and at a more senior level, the interest in the $\mathrm{T} \& \mathrm{~V}$ program was not genuine, reflecting merely the desire to obtain the enhanced resources (e.g., vehicles, offices) associated with the projects. The high cost of the system was Moore's key critical point. 
Criticism and debates of this nature would have had a more decisive impact in forcing greater selectivity and flexibility in the global introduction and implementation of $\mathrm{T} \& \mathrm{~V}$ in the 1980s had they been backed by systemic data sets confirming the checkered adherence to T\&V design principles, and a larger number of rigorous impact studies assessing the farm-level results of the program. But extensive data on the mechanics of $\mathrm{T} \& \mathrm{~V}$ in India were only available from the extension M\&E units, and these indicated reasonable (albeit far from perfect) adherence to visit and training frequencies and contact farmer familiarity with their roles (Feder et al., 1986, Feder and Slade, 1986a, Slade et al., 1998). It was argued by some observers (e.g., Moore (1984), Chambers (1992)) that the M\&E units' reports were likely distorted to present a favorable picture, but the extent of the bias was difficult to establish. An independent data set from one district in Haryana demonstrated, for that particular area, that the mechanics of extension operations were reasonably in place (Feder and Slade, 1986b). A subsequent critical report by Axinn (1988) reiterated some of the points raised by Moore (1984), based on extensive field visits, but rigorous impact studies were not available for quite some time. One such study, from one district in Haryana, indicated (under the strong assumption that benefits observed in the first three years of the project will continue in future years, although at a declining rate) that the incremental cost of $\mathrm{T} \& \mathrm{~V}$ in that district was justified, as there was a high likelihood of a viable rate of return (Feder, Lau, and Slade, 1987). But there were no other rigorous impact studies until the 1994, when Hussain, Byerlee and Heisey found no T\&V impact in Pakistan. A 1993 study by Bindlish and Evenson reported large returns for T\&V extension in Kenya, but it was contradicted by Gautam (2000), who pointed out some data deficiencies in the earlier study, and demonstrated, using better data, that the impact in Kenya was insignificant. These studies have not played much of a role in the apparent lack of support in Asian countries for sustaining T\&V 
in the late 1980s and early 1990s. These countries (such as India, Bangladesh, Indonesia, Pakistan), have reduced the extent of their $T \& V$ extension operation over a relatively short span of time, both by not replacing retirements and transfers, by adding other duties or reassigning staff to other roles, and by abandoning key aspects of the T\&V concept (e.g., the strict schedule of visits and trainings, and the uniform ratios of field and supervisory ranks).

The rearguard battle of the $\mathrm{T} \& \mathrm{~V}$ extension concept was fought out in Sub-Saharan Africa, with the promoters facing increasing doubts and criticisms not only from rural development scholars and officials in developing countries, but also from within the World Bank itself. As early as 1985, the World Bank’s Operations Evaluation Department expressed some criticism (albeit muffled) of the wholesale application of large-scale extension projects in situations that may not have warranted such systems (OED, 1985). The internal debate intensified in the late 1980s and early 1990s as it became apparent that Asian countries, and in particular India, are gradually withdrawing from the $\mathrm{T} \& \mathrm{~V}$ model due to the high cost. This debate is evident in a World Bank 1989 edited volume on extension in Africa (Roberts, 1989), where several papers raise critical issues pertaining to the T\&V approach’s design and cost. The editor, in one of the papers, noted that promotion of the approach universally with little sensitivity to needs in particular situations and countries is attributable in part to the overenthusiasm and inexperience of World Bank staff impressed by the initial favorable feedback from Asia. Thus the author conceded that, in the design of some African T\&V projects, there have been instances of unnecessary rigidity (Roberts, 1989, p. 23). The paper also recognized that $\mathrm{T} \& \mathrm{~V}$ designers had not done justice to the issues of true farmer participation and to the financing of the high recurrent costs. 
However, a 1990 report outlining lessons and suggestions for extension strategies (World Bank, 1990) refrained from explicit criticism (earlier drafts were more critical) and highlighted the greater flexibility and adaptability of the $T \& V$ design as applied in recent projects. Flexibility was indeed forced by reality on the originally rather rigid camp of $\mathrm{T} \& \mathrm{~V}$ extension promoters. Examples of modifications in the design were cited by a number of observers: Roberts (1989) pointed out that in Sudan extension agents continued also their duties as supervisors for the irrigation system. Similarly, in the Comoros extension agents handled input supply functions as there was no reliable private supply system. The involvement of extension staff in non-extension duties was generally frowned upon by T\&V designers. Similar deviations from the exclusive devotion to extension are mentioned by Bagchee (1994). The latter author also pointed out reduction in the frequency of staff training sessions in Kenya, Tanzania and Zaire, and higher ratios of farmers to agents in many countries compared to the standard 1 per 800 favored by $\mathrm{T} \& \mathrm{~V}$ designers. Increased use of mass media as a complementary channel of technology diffusion, along with the T\&V effort, took place in Cote d’Ivoire, Kenya, Nigeria, Senegal and other countries. The original $\mathrm{T} \& \mathrm{~V}$ concept underplayed the reliance on mass media. A fairly common adaptation in African $\mathrm{T} \& \mathrm{~V}$ countries was the shift away from "contact farmers" to “contact groups” as the foci for interactions between agents and the farming clientele (World Bank 1990, p. 21; Bagchee, 1994). This was designed to increase the number of farmers receiving face-to-face service from extension in view of the limited diffusion from contact farmers. 
The modifications did not, however, tackle significantly a key source of the problems, namely, the staff-intensive high recurrent cost structure. High-cost issues were indeed highlighted in Bagchee (1994, e.g., p. 19). The conclusion was, however, only to exercise caution in expanding systems. By the time an influential World Bank Operations Evaluation Study was published (Purcell and Anderson, 1997), it was apparent that fiscal issues were the key challenge, and the various modifications in design offered (and experimented with) in the World Bank's African T\&V extension projects were not sufficient to reduce the costs, as they came after the extension systems were already enhanced and expanded significantly. The flexibility in retrenching public sector employees was limited and thus staff costs could not be changed much. The 1997 OED report listed a number of frequently occurring difficulties in $T \& V$ extension projects and suggested that the relatively high (70\%) share of projects graded "satisfactory" was probably not a realistic reflection of the actual rate of success due to the imprecise nature of such summary judgments. The study concluded that "the Bank had erred in the extent to which it has promoted the $\mathrm{T} \& \mathrm{~V}$ extension management system in relatively uniform packages of investments and extension practices in large state and national programs”. The authors further concluded that the increased flexibility in African $\mathrm{T} \& \mathrm{~V}$ projects was not likely to resolve the problems encountered and therefore the $\mathrm{T} \& \mathrm{~V}$ design was "unlikely to be the most appropriate approach for improving extension in many African countries” (p. 98).

The 1990s witnessed greater interest in alternative extension concepts, with stronger participatory aspects, greater pluralism, and smaller public organizations. In Africa, in particular, there was donor pressure to transfer some aspects of extension to private or other nongovernment providers (Gemo, Eicher and Teclemariam, 2005). Senior management was not 
inclined anymore to expend political capital in convincing reluctant leaders in client countries to accept a high-cost extension model for which there was no rigorous evidence of widespread success at the farm level. Furthermore, with a significant camp of critics inside and outside the Bank becoming increasingly vociferous in challenging the validity of the concepts and their universal feasibility, there were great risks in pushing further the T\&V concept. It was thus in Africa that the T\&V extension model breathed its last, ending 25 years in which agricultural extension received the highest level of attention it ever attracted on the rural development agenda.

\section{Conclusion}

As in most fields of human endeavor, fads are a fact of life. Development practitioners need to be aware that they are not immune from this aspect of the human condition and thus need to guard against falling ready victims to what may appear as a new and relevant approach to an old problem. A usually good starting point to assessing the new ideas is to check back: on the principles underlying them; on the experience in implementation; and on the lessons learned, from the past fads that were followed. Our discussion of the experiences, largely connected to World Bank operations, with the T\&V approach to extension from birth to death, has been intended to facilitate such checking back. Several insights emerge from these reviews, which have a bearing on other current or future extension concepts, and more generally on rural development initiatives.

The $\mathrm{T} \& \mathrm{~V}$ approach tackled some, but not all, of the generic problems that hamper large public extension systems. In particular, the high recurrent costs continued to be an issue, just as 
they were in earlier large extension systems. Approaches that have a better chance of being successful are those that highlight the intended beneficiaries as empowered clients with their needs and demands articulated through service arrangements that heed them, and do so in organizational structures that are affordable within the political and fiscal environment of the country. Such arrangements work best when the empowerment is driven by personal client stakeholding in the delivery of the services being sought, as the client is best positioned to observe the utility of the services rendered (see discussion in Feder, Willett, and Zijp, 2001).

The T\&V extension experience also demonstrates the importance of timely and careful evaluation of pilot experiments with realistic assessment of the likely challenges to be faced if seemingly promising innovations are scaled up significantly. Of particular importance in this context is an analysis of the fiscal implications of the expanded scale, the degree of dependence on external funding, and the likelihood of domestic support to the recurrent costs of the expanded program over time. The often observed inadequacy of operations and maintenance funds in infrastructure projects suggests that this is a common issue, not specific to extension.

Once innovative designs are implemented on a large scale, evaluative studies in a reasonable number of differing locations are crucial in order to form reliable (preferably statistically valid) and convincing judgments on the applicability and limitations of the idea being promoted in different social, economic, political, and physical environments. The availability of appropriate baselines and control groups is often essential for reliable evaluation, but these require prior planning, because their absence is difficult to rectify ex-post. 
Evaluation studies need to be independent of those who have a direct stake in the success of the endeavor, with evaluation teams in which there are no preconceived positions on the innovation being reviewed. While most sponsors of evaluative studies are aware of the need for evaluators' independence, one encounters too often evaluation teams purposefully selected by the concerned stakeholders so as to include scholars who have already expressed themselves favorably on the idea being studied, and this can compromise objectivity. In situations where attribution of impact is analytically difficult, a full evaluation will require quantitative work by qualified professionals to complement qualitative assessments. In many cases such econometric skills will be drawn from academia and research institutes, where they more commonly reside. 


\section{References}

Anderson, J.R. and G. Feder. (2004). “Agricultural Extension: Good Intentions and Hard Realities”, World Bank Research Observer 19(1): 41-60.

Anderson, J.R. and K. Hoff. (1993). “Technological Change, Imperfect Markets, and Agricultural Extension: An Overview”, In K. Hoff, A. Braverman and J.E. Stiglitz, eds., The Economics of Rural Organization: Theory, Practice, and Policy. New York: Oxford University Press for the World Bank.

Axinn, G. (1988). Independent Assessment of Agricultural Extension Services in India, Unpublished, East Lansing, Michigan State University.

Axinn, G.H. and S. Thorat. (1972). Modernizing World Agriculture: A Comparative Study of Agricultural Extension Education Systems. New Delhi: Oxford \& IBH.

Bagchee, A. (1994). Agricultural Extension in Africa. World Bank Discussion Papers 231. Washington, D.C.: World Bank.

Benor, D. and J.Q. Harrison. (1977). Agricultural Extension: The Training and Visit System. Washington, D.C.: World Bank. 
Benor, D. and M. Baxter. (1984). Training and Visit Extension. Washington, D.C.: World Bank.

Bindlish, V. and R. Evenson. (1993). Evaluation of the Performance of T\&V Extension in Kenya. World Bank Technical Paper 208. Washington, D.C.: World Bank.

Birkhaeuser, D., R.E. Evenson and G. Feder. (1991). “The Economic Impact of Agricultural Extension: A Review”, Economic Development and Cultural Change 39 (3), 607-50.

Chambers, R. (1992). “The Self-Deceiving State”, IDS Bulletin 23(4): 31-41.

Development Communication Report. (1978). An Interview with Daniel Benor, No. 22, April, pp. 8-10. Washington, D.C.: World Bank.

Feder, G. and R. Slade. 1986a. “The Impact of Agricultural Extension: The Training and Visit System in India”, World Bank Research Observer 1(2): 139-161.

Feder, G. and R. Slade. 1986b. "A Comparative Analysis of Some Aspects of the Training and Visit System of Agricultural Extension in India”, Journal of Development Studies 22(2): 409-428. 
Feder, G., L.J. Lau, and R. Slade. 1987. “Does Agricultural Extension Pay? The Training and Visit System in Northwest India”, American Journal of Agricultural Economics 69 (3): 688-686.

Feder, G., R. Slade, and A. Sundaram. 1986. "The Training and Visit Extension System: An Analysis of Operations and Effects”, Agricultural Administration 21 (1): 33-59.

Feder, G., A. Willett, and W. Zijp. 2001. “Agricultural Extension: Generic Challenges and the Ingredients for Solutions.” In S. Wolf and D. Zilberman, eds., Knowledge Generation and Technical Change: Institutional Innovation in Agriculture. Boston, Mass: Kluwer.

Gautam, M. 2000. Agricultural Extension: The Kenya Experience: An Impact Evaluation. Operations Evaluation Department. Washington, D.C., World Bank.

Gemo, H., C.K. Eicher, and S. Teclemariam. (2005). Mozambique’s Experience in Building a National Extension System. East Lansing: Michigan State University Press.

Howell, J. 1982a. Managing Agricultural Extension: The $T$ and $V$ Systems in Practice, Discussion Paper No. 8, Agricultural Administration Unit, London: Overseas Development Institute. 
Howell, J. 1982b. 'Responses to Discussion Paper No. 8, "Managing Agricultural Extension: T and V System in Practice”, Agricultural Administration Network Newsletter No. 9, London: Overseas Development Institute.

Howell, J. 1983. Strategy and Practice in the $T$ and V System of Agricultural Extension, Discussion paper No. 10, Agricultural Administration Network. London: Overseas Development Institute.

Hussain, S.S., D. Byerlee, and P.W. Heisey. 1994. "Impacts of the Training and Visit Extension System on Farmers’ knowledge and Adoption of Technology: Evidence from Pakistan”, Agricultural Economics 10(1): 39-47.

Lipton, M. with R. Longhurst. 1989. New Seeds and Poor People. Baltimore: Johns Hopkins University Press.

Martens, B., U. Mumert, P. Murrell, and P. Seabright. 2002. The Institutional Economics of Foreign Aid. Cambridge University Press.

Moore, M. 1984. “Institutional Development, the World Bank, and India’s New Agricultural Extension Program”, Journal of Development Studies 20(4): 303-17. 
Mureithi, J. and J.R. Anderson. 2004. “Farmer-Extension-Research Interfaces”, In C. Ndiritu, J. Lynam, A. Mbabu, eds., Transformation of Agricultural Research Systems in Africa, East Lansing: Michigan State University Press.

Operations Evaluation Department (OED). 1985. Agricultural Research and Extension: An Evaluation of the World Bank Experience. Washington, D.C.: World Bank.

Picciotto, R. and J.R. Anderson. 1997. “Reconsidering Agricultural Extension”, World Bank Research Observer 12(2): 249-59.

Purcell, D.L. and J.R. Anderson. 1997. Agricultural Extension and Research: Achievements and Problems in National Systems. Washington, D.C.: World Bank.

Rivera, W.M., M. Kalim Qamar, and L. Van Crowder. 2001. Agricultural and Rural Extension Worldwide: Options for Institutional Reform in Developing Countries. Rome: Food and Agricultural Organization.

Roberts, N. ed. (1989). Agricultural Extension in Africa. A World Bank Symposium. Washington, D.C.: World Bank.

Slade, R., G. Feder, and R. Chhikara. 1988. "Reforming Agricultural Extension: The Training and Visit System in India”, Quarterly Journal of International Agriculture 27(3/4): 228246. 
World Bank. 1990. Agricultural Extension: The Next Step. Agricultural and Rural Development Department, Policy and Research Series no. 13. Washington, D.C.: World Bank. 